\title{
CONTRA EL VIENTO DE ÁNGELES CASO: ENTRE AFROPESIMISMO Y EUROCENTRISMO
}

\author{
POR \\ MaÏMOUNA SANKHÉ \\ Universidad de Ghana
}

Contra el viento (2009) de Ángeles Caso, cuya escena se desarrolla alternativamente entre África y Europa, forma parte de las obras que se inspiran en la realidad de la inmigración africana en Europa. Este vínculo estrecho entre realidad y ficción corrobora la teoría de Doležel quien reconoce, en Heterocósmica ficción y mundos posibles (1999), que "la ficción trabaja con materiales extraídos de la realidad" (Doležel 11) aunque discrepa firmemente de la doctrina de la mimesis que sostiene que "las ficciones son imitaciones o representaciones del mundo verdadero, o de la vida real" (Doležel 10).

La publicación de Contra el viento (2009) coincidió con el momento en que el tema de la inmigración africana en España era una cuestión de candente actualidad en los medios de comunicación y en la opinión pública. Es decir, después de la llegada masiva en pateras de inmigrantes africanos. Muchos de ellos pescadores artesanales senegaleses que vieron sus medios de subsistencia destruidos a raíz del saqueo de los recursos pesqueros del país por parte de los grandes barcos extranjeros y con la complicidad de los gobiernos.

Antes de que saliera a la luz Contra el viento, ya se habían publicado otras obras sobre la inmigración africana en Europa. Podemos referirnos a Yo, Mohamed (1995) de Rafael Torres; Las voces del Estrecho (2000) de Andrés Sorel; "Un gran jardín” (2000) cuento escrito por Alicia Giménez Bartlett; Les clandestins (2000) de Youssouf Amine Elalamy, Al calor de día (2001) de Miguel Naveros, entre otros.

La particularidad de Contra el viento radica en que no se trata de una novela sobre las travesías o sobre las pateras como lo son la mayoría de las obras sobre la inmigración en España. Conviene subrayar que, aunque los inmigrantes llegados en pateras representan un porcentaje ínfimo respecto al resto de los inmigrantes, la gran mayoría de las obras se concentran en ellas porque como afirma Marco Kunz las pateras representan la parte "más dramática y conmovedora, es decir, la más rentable como noticia y también la más novelable" (Kunz 233).

Por su parte, Monserrat Iglesias, directora del grupo de investigación "Imagologías" de la Universidad Carlos III de Madrid, afirma que la representación de la inmigración en 
la literatura y el cine españoles no refleja la realidad sociológica de este segmento social, ya que dicha representación artística es, según ella, no sólo "africanizada" (dado que se concentra en el origen subsahariano del inmigrante, mientras que éste no representa ni siquiera el 5\% de los inmigrantes) sino que también está asociada a la pobreza y la marginación (Imagen del inmigrante).

La protagonista de Contra el viento es São, una mujer caboverdiana que tuvo una vida dura desde su niñez. Fruto de una violación, su madre tuvo que dejarla con una paisana para irse a vivir a Italia con su marido. Así que creció sin figura paterna ni materna, teniendo que aprender a responsabilizarse de su vida y a madurar rápidamente. São decidió emigrar a Europa en busca de una vida mejor.

São llegó en avión como la gran mayoría de los inmigrantes en España. No tuvo que arriesgar su vida ni en el desierto y ni en las pateras. Paradójicamente, la vida diaria de São en Europa como inmigrante africana que lucha para fraguar un camino es apenas representada en la novela. La narración la acaparan los estereotipos, las miserias, las tragedias y la irresponsabilidad de los hombres africanos quienes pegan, violan o abandonan a sus mujeres e hijos.

África está representada a través de dos países: Cabo Verde, de donde es São la protagonista principal de la novela, y Angola, de donde procede su ex pareja y padre de su hijo André. Estos dos países africanos están descritos como lugares inhóspitos donde la vida es una eterna lucha para sobrevivir a las calamidades naturales, la miseria, las enfermedades y la muerte.

Los recuerdos de Bigador de Luanda (capital de Angola) se reducen a la guerra y la miseria:

De su infancia recordaba sobre todo el hambre, los tiros, los tanques de los ejércitos en lucha levantando polvo en medio de las calles de Luanda, los escombros sobre los cuales los niños jugaban a dispararse y cazaban ratas que luego las mujeres asaban en los fuegos nocturnos. Desde los seis años robaba frutas en los mercados, y pastillas de jabón. Su madre le regañaba, pero él sabía que su hurto era bueno para ella y sus siete hermanos. Del padre apenas tenían noticias. (Caso 150-151)

\section{MeSTIZAJE Y EMIGRACIÓN COMO ÚNICAS SALVACIONES}

Si bien es cierto que Contra el viento no pretende proponer el mestizaje como solución a un problema racial tal y como lo proyectaban obras como La raza cósmica (1925) de José Vasconcelos, ${ }^{1}$ lo que sí es innegable es que, en la novela, los personajes

1 Vasconcelos estaba convencido de que el mestizaje era necesario para con conseguir el "mejoramiento étnico": "Los tipos bajos de la especie serán absorbidos por el tipo superior. De esta suerte podría redimirse, por ejemplo, el negro, y poco a poco, por extinción voluntaria, las estirpes más feas irán

Revista Iberoamericana, Vol. LXXXII, Núm. 254, Enero-Marzo 2016, $123-134$ ISSN 0034-9631 (Impreso)

ISSN 2154-4794 (Electrónico) 
negros no pueden valerse por sí mismos, necesitan el mestizaje o, de alguna manera ,el contacto con Europa para poder avanzar. El "otro", en este caso el negro, necesita el mestizaje para mejorar su estatus o, mejor dicho, para humanizarse, retomando la expresión de Solomianski: "en el caso del proceso identificador racista se trata de hacer del 'otro' algo no humano, negarle su humanidad, construirlo como negación. Y si bien es evidente que la 'blanquedad' se autoconsidera lo humano y designa a la 'negritud' como lo subhumano" (54).

Las mujeres caboverdianas de la novela son comparadas con seres carentes de "recursos morales" (Caso 143) que no saben más que parir hijos, resignarse e intentar sobrevivir. Liliana, una caboverdiana que emigró con sus padres a Portugal cuando tenía cuatro años, volvía de vez en cuando para charlar con las mujeres sobre asuntos relacionados con los malos tratos, los métodos anticonceptivos o la educación de los niños, pero según la narradora las mujeres:

Carecían de recursos morales que les permitiesen reflexionar sobre lo que les estaba contando. La vida las había arrojado en medio de un mundo duro y violento, y ellas subsistían enraizadas en él, como frágiles animales desprotegidos. La única idea que palpitaba en sus cabezas era la de sobrevivir, ellas y sus niños: sobrevivir al hambre, sobrevivir a las palizas, sobrevivir a la disentería. (Caso 143)

Resulta sorprendente que las únicas mujeres africanas que han conseguido una vida holgada en la novela sean las mulatas. Una de ellas es Doña Natercia, maestra de São: "era una mujer cercana a los cuarenta años, hermosa y dulcemente enérgica. Adoraba a los niños, aunque ella misma no tuviera hijos. Tenía la piel muy clara. Sus padres eran mulatos, descendientes de antiguos colonos europeos que en el pasado habían tomado como amantes a mujeres negras" (Caso 71).

En el retrato se nota cómo se humaniza a la maestra quien, a pesar de no tener hijos, quiere a los niños y se preocupa por sus problemas de educación, lo que no parece inquietarles mucho a las demás mujeres del pueblo. De hecho, Doña Natercia hizo todo lo posible para que São siguiera estudiando. Los padres traen al mundo a los hijos pero son los demás quienes se ocupan de lo más importante.

La otra mujer cuya situación económica es también acomodada, es la mulata doña Ana, ama de la casa donde trabajó São y esposa de don Jorge, un simpático portugués:

cediendo el paso a las más hermosas. Las razas inferiores, al educarse, se harían menos prolíficas, y los mejores especímenes irán ascendiendo en una escala de mejoramiento étnico [...]. El indio, por medio del injerto en la raza afín, daría el salto de los millares de años que median de la Atlántida a nuestra época, y en unas cuantas décadas de eugenesia estética podrían desaparecer el negro junto con los tipos que el libre instinto de hermosura vaya señalando como fundamentalmente recesivos e indignos, por lo mismo, de perpetuación", 40.

Revista Iberoamericana, Vol. LXXXII, Núm. 254, Enero-Marzo 2016, 123-134 ISSN 0034-9631 (Impreso)

ISSN 2154-4794 (Electrónico) 
Era una mulata educada en Londres, más europea que africana, que detestaba el contacto físico y la expresión demasiado evidente de los sentimientos [...]. Plantada en las alturas de su condición, bien educada y despreocupada de casi todo lo que no fuera su propio aspecto, permitía que sus criadas [São y Joana] trabajasen con cierta comodidad, sin perseguirlas con demasiadas exigencias. No solía gritarles ni reñirlas [...]. Era una vida decente. $(105-107)$

A parte de estas dos mujeres mulatas, la única que logra salir adelante y tener su propia empresa, donde acaba São trabajando como recepcionista, es doña Benvinda, una negra que años antes había emigrado a España. Ella nació en un pueblo caboverdiano llamado Portela: "una aldea miserable y gris de la isla de Fogo, en plena ladera de un inmenso volcán, donde se crecía entre sequías y hambrunas, fiebres y disenterías. Desde muy pequeña se había acostumbrado a que la muerte formara parte de la vida"(124-125).

A Benvinda la suerte le sonrió cuando se fue a vivir con su marido a España. Desgraciadamente, el marido de Benvinda murió prematuramente. Como la tragedia ocurrió en la mina asturiana donde trabajaba su marido, a Benvinda la indemnizaron y con esto pudo volver a Cabo Verde y montar su propio negocio. Asimismo, con dicho dinero ayudó a sus hermanas a emigrar a Holanda y, posteriormente, pagó el billete de avión de São para que emigrara a Portugal. Del mismo modo, fueron las hermanas de Benvinda quienes ayudaron a São a emigrar a Europa mandándole una invitación: "me gustaría que tuvieses una vida mejor. Te la mereces. Debes intentarlo" (137), dijo Benvinda a São.

Benvinda era desgraciada en Cabo Verde pero muy feliz en España. Lo que necesita la mujer africana es pisar el suelo europeo para que sus sueños se conviertan en realidad:

Durante cinco años, fue una mujer feliz. Todo la entusiasmaba, la mansedumbre del paisaje y el cambio de las estaciones, la luz eléctrica y el agua que manaba por los grifos como una cascada sin fin, las tiendas y los mercados donde podían encontrarse tantos alimentos diferentes, los electrodomésticos que hacían por ella las tareas, el parque en el que jugaban los niños, las cafeterías en las que solía quedar con otras caboverdianas para tomar café y charlar, los abrigos de invierno y los zapatos de tacón [...]. Todo le parecía un regalo, como si la vida se hubiese convertido inesperadamente en un precioso paquete del que iba extrayendo una y otra vez cosas deliciosas, pequeños objetos extraordinarios que ella admiraba y cuidaba con devoción, sosteniéndolos firme y delicadamente entre las manos. (128)

Para conseguir una vida mejor, todo el que pueda, tiene que emigrar a Europa. Los que no pueden, sobreviven con el dinero que les mandan sus hijos desde Europa; reparemos en la afirmación de Jovita: "lo único malo es que me duele una muela. Voy a tener que ir a Vila al dentista, pero estoy esperando a que me llegue el dinero de Europa, porque ya casi no me queda nada. Bueno, para comer sí” (43).

Revista Iberoamericana, Vol. LXXXII, Núm. 254, Enero-Marzo 2016, $123-134$ ISSN 0034-9631 (Impreso)

ISSN 2154-4794 (Electrónico) 
Cuando Bigador llevó a su hijo André a Angola sin el consentimiento de su madre, ella decidió ir a Luanda para rescatarle porque además de quererle, también:

[d]eseaba que tuviera una vida tranquila, lejos de la violencia de su padre y de la del país adonde él le había llevado, lejos de la miseria y las enfermedades que asolaban como plagas bíblicas los barrios de Luanda, una vida decente y en paz, estudiando, aprendiendo a creer en el poder de la razón y no en el de los puños, los machetes o los kaláshnikov, aprendiendo a responsabilizarse de las consecuencias de su paso sobre la tierra. Tal vez Bigador la matase, pero su obligación era intentar rescatar a su hijo de aquel mundo de escombros. (255)

La narradora se refiere a una Angola recién salida de la guerra, pero en su relato se recalca el machismo, el salvajismo y la irracionalidad de los hombres quienes no "creen en el poder de la razón" sino más bien en el de "los machetes y los kaláshnikov". La narradora desde su "superioridad eurocentrista" da una lección de moral a estos "salvajes" que no están ni siquiera en condición de "responsabilizarse $[. .$.$] de su paso$ sobre la tierra" (255).

Gran parte de la novela está dedicada a contar las tragedias de las mujeres caboverdianas y, por ende, de las mujeres africanas y su mala suerte con los hombres y con la vida en general. Es una novela muy pesimista, por no decir afropesimista, en cuanto al futuro de los hombres, mujeres y niños en Cabo Verde en particular y, en general, en África. La única salvación existente en la novela es la emigración a Europa. Las mujeres están todas abandonadas por sus maridos con una retahíla de hijos de los que la mayoría muere antes de llegar a la adolescencia.

La niña São quería estudiar medicina, pero no pudo hacerlo en África. Todo tiene que venir de Europa y nada más que de Europa; hasta el biberón con el que su madre la alimentaba de niña tuvo que venir de Europa: "en cuanto le pareció que estaba [São] lo suficientemente fuerte y sana, escribió a una de las hijas de Jovita que vivía en Portugal, metió en un sobre un par de billetes y le pidió que le mandase un biberón" (61).

En Contra el viento, las cosas son blancas o negras, no hay término medio. La mujer, en Europa, es una mujer libre mientras que la africana sigue siendo una esclava del hombre y de la sociedad: "en los países de Europa muchas mujeres estudiaban igual que los hombres, y llegaban a tener profesiones que todavía en Cabo Verde eran inimaginables" (84). La maestra de São le dice que si estudia bien podría tener la suerte de ir a Portugal y estudiar allí Medicina. Y desde este momento afirma la narradora: "toda su existencia iba dirigida en aquel único sentido [hacia Portugal], igual que si estuviera siguiendo una gran senda alfombrada que la condujera hacia un paraíso, hacia un territorio lleno de tesoros al alcance de la mano" (82). Hasta piensa la narradora que si São decidiese volver a Cabo Verde, sería un fracaso total y su hijo sería uno más de la larga lista de pobres en el mundo, si consiguiese escapar de la muerte: "y si su hijo

Revista Iberoamericana, Vol. LXXXII, Núm. 254, Enero-Marzo 2016, $123-134$ ISSN 0034-9631 (Impreso)

ISSN 2154-4794 (Electrónico) 
lograba sobrevivir a todas las penurias que les esperaban allí, nunca podría estudiar. Sería otro hombre condenado a la ignorancia, otro futuro gusano entre los pobres del mundo, arrastrándose en medio de una vida miserable" (192).

Todo lo contrario de África, Europa está descrita como "El Dorado", el lugar de todas las oportunidades, donde conseguir médicos y poder estudiar. Europa representa el único rescate posible para los pobres africanos tanto para los que se quedan y sobreviven gracias al dinero que les mandan sus hijos emigrantes como para los que han tenido la "suerte" de emigrar a Europa.

La suerte de São de conseguir un trabajo a los pocos días de llegar a Europa no es lo que suele ocurrir, sobre todo teniendo en cuenta el tiempo en que transcurre la novela (el año 2007). En seguida encuentra trabajo, permisos de residencia, un novio, entre otras cosas. Todo fácil a partir de ese momento mientras que en su aldea de Cabo Verde todo era un atolladero. En su vida diaria como inmigrante africana en Portugal y más tarde en España, no se topó ni con rechazo ni con miradas extrañas aparte del incidente ocurrido en el bar de la playa donde consiguió su primer empleo como camarera: un cliente la llamó negra y le dijo que si no sabía servir que se fuera a su selva.

Este fue el único incidente del que fue víctima São, por lo demás, era bastante aceptada en sus demás empleos. Lo cual hace pensar en una construcción simplista de la realidad de la mujer inmigrante, desde la óptica de la mujer española dado que estos pasajes no reproducen fielmente la realidad de la mujer negra inmigrante en Europa. A este propósito conviene recordar a Juan Ramón Jiménez citado por Rojas Mix, quien habla de "literatura forzada":

Yo no acepto como expresión indígena esencial el Indigenismo artificial americano que hoy lo invade todo por aquí... Gitanismo, Indigenismo que, al igual que el Negrismo de los blancos, que no es negro, han extraviado tanto a ciertos poetas, artistas y críticos popularistas iberoamericanos y españoles. Indio, negro, gitano, desde fuera, son literatura forzada, no poesía directa. Para que lo fuera, es imprescindible que el poeta sea gitano, negro o indio, no blanco pintado de cualquiera de las tres razas. (citado en Rojas Mix 325-326)

\section{LA FIGURA DEL SACERDOTE}

En Contra el viento la figura del cura, además de su papel religioso, representa el primer eslabón hacía la emancipación de los personajes principales. Los sacerdotes católicos se encargan de la educación y la manutención de los niños, mitigando así la pena causada por la irresponsabilidad de los negros de la novela en cuanto a sus papeles como maridos y como progenitores. Sobre el colegio de monjas portuguesas, señala la narradora:

Revista Iberoamericana, Vol. LXXXII, Núm. 254, Enero-Marzo 2016, $123-134$ ISSN 0034-9631 (Impreso)

ISSN 2154-4794 (Electrónico) 
Había también algunas crías de familias desgraciadas, que estudiaban tuteladas por la orden [...]. Sus progenitores-alcohólicos, pordioseros, prostitutas-eran parásitos, cucarachas que no deberían existir, y ellas llevaban en la sangre su rastro inmundo, su olor a podredumbre, y están condenadas a luchar denodadamente contra un ángel maligno que las acompañaba desde el nacimiento. (Caso 71-72)

En opinión de la narradora los progenitores de estas crías no deberían existir, lo cual recuerda a la eugenesia acuñada por Francis Galton y que pretendía hacer una selección natural para eliminar a todas las inferioridades que se oponían a la marcha del progreso.

Cabe señalar que el resurgimiento del Negrismo a principios del siglo XX en América Latina, fue una oportunidad para artistas e intelectuales latinoamericanos poner en tela de juicio una y otra vez la cultura del negro, a pesar de que algunos de ellos tuvieran una intención verdadera de reivindicar e incorporar los valores culturales del negro como parte integrante de la cultura latinoamericana. ${ }^{2}$ Por ejemplo, revistas como Leche criolla (1929) aprovecharon que el tema estuviera de moda para pronunciarse a favor de la desaparición de la herencia negra que consideraba nociva para la sociedad.

En ese mismo orden de ideas, Guilhermino César, el entonces director de la revista vanguardista brasileña Leche Criolla consideró nocivo el carácter del negro comparándolo con un pájaro negro perezoso e irresponsable que deja sus huevos en el nido de otro pájaro para que éste, inadvertidamente, se ocupe de los críos:

Leite Criôlo identificó al negro con el "vira-bosta" (tordo), pájaro negro conocido por poner sus huevos en el nido del tico-tico (gorrión), que inadvertidamente, le atiende la cría. 'Vira-bosta es el criollismo', dice João Dornas Filho, él mismo mulato. Con semejante afirmación refrenda el mito de la 'pereza secular del carácter brasileño'. (Schwartz 300)

Esta metáfora usada al principio del siglo XX en Latinoamérica para refrendar el mito de la "pereza secular del carácter brasileño" (300) recuerda la postura del sacerdote católico en Contra el viento donde desempeña el papel de protector de los desamparados.

Ninguna de las mujeres africanas de la novela tiene suerte con los hombres quienes están retratados como seres irresponsables, lascivos y violentos que van cambiado de mujeres y huyendo de sus obligaciones como padres y esposos. De Jovita apunta: "no había tenido mucha suerte con sus maridos [...]. El primero desapareció precisamente porque se hartó de aquel zafarrancho de criaturas y se largó con una muchacha más joven. El segundo, porque fue ella la que se hartó de sus malos tratos" (39 y 45). El tercero, que era bueno, murió prematuramente:

2 Ver Sankhé Adebowale, 134.

Revista Iberoamericana, Vol. LXXXII, Núm. 254, Enero-Marzo 2016, 123-134 ISSN 0034-9631 (Impreso)

ISSN 2154-4794 (Electrónico) 
No había tenido mucha suerte con sus maridos. El único bueno había sido el tercero, el pobre Sócrates, que trabajaba de sol a sol con las frutas y los pescados y se ocupaba además de la huerta y de ir a buscar la leche de las cabras allá arriba, en el monte, debajo del drago, y la trataba como un reina y le aguantaba las riñas y sus propias borracheras y hacía todo lo que ella le mandaba. Véteme a por agua. E iba. Ráscame la espalda. Y se la rascaba. Dame placer esta noche. Y se lo daba [...]. Pero Sócrates estaba muerto desde hacía muchos años. (Caso 39)

De ahí la imperiosa necesidad de la intervención del cura erigido en emblema del redentor de los desamparados, ocupando el sitio del tico-tico (gorrión) para cuidar de los críos del tordo (vira-bosta). Como puede apreciarse, es el padre Virgilio, sacerdote de la aldea quien consigue el primer trabajo para São después de que abandone los estudios por falta de medios. El empleo consiste en ir a la capital a trabajar como ayudante doméstica en la casa de los Monteiro, una pareja formada por la mulata Ana y el portugués Jorge.

Más significativo aún es el encuentro entre el padre Barcellos y Bigador, ex pareja de São y padre de su hijo André. Bigador era un niño vagabundo que andaba atracando por las calles de Luanda y acechando "a los blancos -que siempre llevaban buenas cantidades de dinero-y a cogerles las carteras" (151), pero consiguió enderezarse, dejar de robar y aprender un oficio gracias a la bondad del padre Barcellos a quien intentó atracar en vano: "aquel encuentro cambió su vida. El cura decidió ocuparse de él" (151). Apenas conoció a su padre porque trabajaba en las minas, pero de vez en cuando "aparecía allí unos días, y luego regresaba de nuevo al agujero después de dejar a su mujer embarazada" (151). Su padre no hace más que dejar embarazada a su madre una y otra vez, y luego desentenderse de sus hijos como todos los demás negros de la novela.

Bigador creció sin un referente paterno; de hecho, cuando conoció al cura no podía separarse de él, le seguía por todas partes ya que "un adulto, con su voz grave y sus gestos bruscos, se preocupara por él y le diera órdenes le pareció algo extraordinario. Desde el primer día se puso a seguirlo como un perrillo callejero" (152). El cura se hace cargo de él y de otros tantos niños como él. El logro más trascendental de esta relación fue el trabajo que Bigador consiguió y que le permitió alquilar una casa para su madre y sus hermanos y, además, ahorrar dinero para emigrar a Portugal: "pudo alquilar para su madre y sus hermanos más pequeños una casa mucho mejor que la miserable chabola en la que habían vivido hasta entonces y, cuando fue mayor de edad y logró reunir suficiente dinero, emigró a Portugal" (153).

Allí consiguió una vida decente y mandó comprar para su madre una casa que compartía con el hermano mayor de Bigador y su familia: "la casa era fea [...], de color gris $[\ldots]$ con una acacia raquítica y polvorienta tratando de sobrevivir en un rincón" (258). En definitiva, el amparo de la Iglesia es a la vez moral y físico; incluso Jovita vendía sus frutas y verduras en la plaza, "arrimada al cobijo de la iglesia que la protegía tanto del viento como del sol desnudo de la media mañana" (46).

Revista Iberoamericana, Vol. LXXXII, Núm. 254, Enero-Marzo 2016, $123-134$ ISSN 0034-9631 (Impreso) 
Los negros de la novela están descritos como irresponsables mientras que el sacerdote aparece como el santo protector que cubre las necesidades de los niños abandonados por unos padres irresponsables. Postura que recuerda su autoproclamado papel de "salvador" de los negros en la época de la esclavitud y que consistía en convertirlos a la religión católica apostólica y romana y alejarlos de sus religiones africanas que eran demonizadas y consideradas como una aberración cuando la religión católica representaba la civilización religiosa.

La narración de Contra el viento empieza en España con los recuerdos de infancia de la narradora al lado de una madre cariñosa y sumisa y un padre al que describe como déspota, cruel e insensible pero que, a pesar de este mal carácter, se preocupaba por mantener a su familia y preservar la unidad familiar. Al menos desde fuera su padre daba la imagen de una "persona decente y honrada" (27) que se hacía respetar: "y mi padre no estaba dispuesto a dar nada que hablar sobre su intachable moralidad, su práctica perfecta de todos los sagrados preceptos que marcaba la sociedad" (26-27).

El nuevo novio de São está igualmente presentado como un hombre responsable que nunca dejaría a su novia. Se trata del portugués Luis al que la narradora define como un hombre con un aspecto aburrido que hablaba poco, pero que "era también profundamente bondadoso [...], que estaba a su lado y que nunca iba a dejarla [a São] sola" (252). Por fin São ha encontrado un hombre que no la dejaría jamás sola como hizo el salvaje Bigador y como hacen los demás hombres negros de la novela quienes se caracterizan por ser borrachos, juerguistas e insensatos o violadores; de hecho, la protagonista de la novela es fruto de una violación. El tema de la violación es muy recurrente en la novela y muchas mujeres han sido violadas o viven bajo la constante amenaza de sufrir una violación.

Aunque la novela se inspira en la inmigración africana en Europa, el tema central es la denuncia contra la violencia ejercida tanto contra las mujeres africanas como europeas. Una actitud muy encomiable si tenemos en cuenta la lacra que representa la violencia de género en todas partes del mundo. Por tanto, cuantas más voces se levanten para denunciar, mejor para todos.

La narradora ha vivido la violencia en sus propias carnes cuando era pequeña. Su madre fue víctima de la violencia de su padre, lo cual debió de ser en tiempos de la dictadura franquista en España cuando las mujeres tenían menos derecho y no podían denunciar; la siguiente afirmación se refiere a dicha época: "cotilleaban [...] sobre [...] el nuevo modelito de la hija de Franco" (28). No obstante, llama la atención el hecho de que cuando se trata de Europa, la única violencia relatada es la de antaño, encarnada por su padre, cuando es irrefutable que la violencia de género sigue siendo en la actualidad un grave problema social en España, y las mujeres mueren frecuentemente a mano de sus parejas. Igualmente, resulta cuando menos chocante que los negros sean los únicos que pegan o abandonan a sus mujeres. Obviamente, las dos formas de violencia son

Revista Iberoamericana, Vol. LXXXII, Núm. 254, Enero-Marzo 2016, $123-134$ ISSN 0034-9631 (Impreso)

ISSN 2154-4794 (Electrónico) 
repugnantes, pero es extraño que el padre de la narradora ejerza la violencia verbal y, de cara a la galería, se porta decentemente. Los negros de la novela en cambio, no sólo maltratan física y verbalmente sino que todos son maltratadores.

Aunque Contra el viento de Ángeles Caso tiene como protagonista principal a una mujer caboverdiana que emigra a Portugal y luego a España, en el argumento de la novela se vislumbra un empeño en estereotipar a África y a los africanos. Estereotipos que recuerdan las novelas antiesclavistas del siglo XIX o algunas novelas negristas latinoamericanas de principios del siglo XX. La construcción de África en la novela no puede reducirse a la reproducción de viejos estereotipos coloniales que, lejos de favorecer la integración, provocan el rechazo y la estigmatización.

Obviamente, la presencia de estos estereotipos no puede ser un motivo para hacer caso omiso de la buena intención que hay en la novela de hablar-porque apenas les da la palabra- de los colectivos menos representados en la sociedad europea y también de denunciar la violencia de género que es la lacra de todos los tiempos.

En resumen, Contra el viento de Ángeles Caso podría considerarse una apología de la inmigración africana a Europa por su tinte eurocéntrico y profundamente afropesimista. La inmigración es una condición sine qua non para que los africanos de la novela puedan progresar. África está presentada como un lugar inhóspito cuyos ciudadanos, debido a sus condiciones de vida miserables, necesitan de una manera u otra el contacto con Europa para mejorar sus vidas. Lo cual constituye una perpetuación del trabajo de los medios de comunicación occidentales que se empeñan en no mostrar de África más que su lado negativo haciendo caso omiso de todo lo positivo.

La narradora parece dominar mejor la vida de los africanos en África que en Europa. La vida de los personajes africanos de la novela se resume en un párrafo:

La casa de María Sábado era muy triste. En realidad, todo era muy triste. El barrio de calles sucias, lleno de edificios iguales, desconchados y mugrientos, en los que se hacinaban cientos de inmigrantes, familias enteras venidas de África a costa de muchas deudas y de los ahorros de muchas vidas, amontonadas como insectos en los pisos minúsculos. Hombres que abandonaron un día la aldea de la sabana y cruzaron desiertos y montañas y mares y que malvivían vendiendo paraguas los días de lluvia y abanicos los de sol. Mujeres que huyeron de una ciudad miserable para evitar un matrimonio forzado, y las palizas, y la esclavitud, y que ahora limpian casas y escaleras y oficinas y hospitales por unas pocas monedas. Un cúmulo de gentes de orígenes distintos, de tribus enemigas, una colmena de olores y lenguas y músicas diferentes, noches de amor y noches de sexo y noches de muerte y noches de alcohol y noches de llanto y noches de cuchillos, infinidad de sueños rotos y una multitud de esperanzas, almas fracasadas y almas resignadas y almas coléricas y almas deshechas y almas poderosas, un enjambre de gentes sin arraigo, sin razones para quedarse ni para regresar, dueños de nada, sombras perdidas en un camino que debía conducirlas al paraíso y casi siempre las llevó al infierno. (Caso 159)

Revista Iberoamericana, Vol. LXXXII, Núm. 254, Enero-Marzo 2016, $123-134$ 
Sus experiencias diarias en Europa no parecen interesar mucho, sino más bien sus miserables vidas en África. Kunz subraya que autores como Elalamy y Binebine no prestan mucha atención a la vida de los inmigrantes en Europa sino más bien a sus vidas en el país de origen porque sus personajes nunca llegan a Europa. Lo que no es el caso de los personajes de Contra el viento que sí llegaron a Europa y los de la mayoría de las obras literarias españolas sobre las pateras. Éstas hablan mayoritariamente de la travesía o de inmediatamente antes o después de ella, retomando las palabras de Kunz.

A pesar de que Contra el viento de Ángeles no es una obra sobre las pateras como lo son la mayoría de las obras sobre la inmigración en España, conviene señalar que hay una similitud con las demás en cuanto al empeño, en primer lugar, en unir inmigración africana con pobreza, en segundo lugar en la africanización de la inmigración y, por último, en interesarse por las vidas de sus personajes en sus países de origen. Vidas, en el caso de Contra el viento, caracterizadas, por lo general, por la violencia, la irresponsabilidad y el salvajismo.

Por lo tanto, vende a Europa y su cultura como un paraíso donde los sueños pueden hacerse realidad. Esta misma Europa rescata a los africanos que no pueden valerse por sí mismos (a través del mestizaje, la evangelización o la emigración económica). En cambio, las desgracias de los africanos sirven para que los europeos tengan su autoestima bien alta y se sientan afortunados por haber nacido en Europa. Es así como se fortalece la amistad entre la inmigrante africana São y la narradora.

De cualquier manera, empecé a ver el mundo de otra forma, a comprender que mis grandes tragedias, todas aquellas cosas que desde pequeña me parecían circunstancias terribles, a cuyo dolor sobre mí vivía enganchada como los toxicómanos a la droga, eran minucias si las comparaba con la existencia de infinidad de seres humanos en buena parte del mundo. Mis dramas eran en buena medida risibles al lado de la dura lucha de tanta gente por no morirse [...]. De pronto, todo parecía estar cambiando dentro de mí. Ya no era la Desdichada, la Sufridora de la tierra. De pronto era un ser humano común y corriente, que gozaba de muchos más privilegios que la mayoría. (Caso 221)

Todorov subraya que "el conocimiento de lo ajeno sirve para el enriquecimiento propio: en este campo, dar es recibir" (25). Por lo tanto, es importante que el cruce cultural sea como recomienda Édouard Glissant con la "criollización”, es decir que los elementos heterogéneos mezclados se intervaloricen, o sea, que no haya degradación o disminución del ser tanto desde dentro como desde fuera, en esta mezcolanza (Glissant 18).

Por lo demás, es una novela amena en lo que a la lectura se refiere por su estilo rico y agradable. No en vano ganó el premio Planeta de novela (2009) que es el segundo premio mejor dotado del mundo, económicamente hablando.

Revista Iberoamericana, Vol. LXXXII, Núm. 254, Enero-Marzo 2016, $123-134$ ISSN 0034-9631 (Impreso)

ISSN 2154-4794 (Electrónico) 
BiBLIOGRAFÍA

Abrighach, Mohamed. La inmigración marroquíy subsahariana en la narrativa española actual. Ética, estética e interculturalismo. Agadir: ORMES, 2006.

Andres-Suárez, Irene, Marco Kunze Inés d'Ors. La inmigración en la literatura española contemporánea. Madrid: Verbum, 2002.

Caso, Ángeles. Contra el viento. Barcelona: Planeta, 2009.

Doležel, Lubomir. Heterocósmica ficción y mundos posibles. Madrid:Arco Libros, 1999.

Glissant, Édouard. Introduction à une poétique du divers. París: Gallimard, 1996.

Kunz, Marco. Juan Goytisolo, metáforas de la migración. Madrid: Verbum, 2003.

Rojas Mix, Miguel. Los cien nombres de América. Eso que descubrió Colón. Barcelona: Lumen, 1991.

Sankhé Adebowale, Maïmouna. "La narrativa negrista hispanoamericana: tiempo y contratiempo de una expresión literaria". Tesis de doctorado. Madrid: Universidad de Alcalá, 2013.

Schwartz, Jorge. Las vanguardias latinoamericanas. Textos programáticos y críticos. México: Fondo de Cultura Económica, 2002.

Solomianski, Alejandro. Identidades secretas. La negritud argentina. Rosario: Beatriz Viterbo Editora, 2003.

Todorov, Tzvetan, coord. Cruce de culturas y mestizaje cultural. Madrid: Ediciones Júcar, 1988.

Vasconcelos, José. La raza cósmica. Misión de la raza iberoamericana. 1925. México: Asociación Nacional de Libreros, 1983.

"La imagen del inmigrante en el cine y la literatura no refleja su realidad social". Universidad Carlos III de Madrid. <http://portal.uc3m.es/portal/page/portal/ actualidad_cientifica/noticias/inmigrante_cine_literatura>. 12 feb. 2014. 